\title{
Analytical and Numerical Methodology for Modeling Temperatures in Landfills
}

\author{
James L. Hanson ${ }^{1}$, M. ASCE, PE, Wei-Lien Liu, A.M. ASCE, and Nazli Yesiller ${ }^{3}$, \\ A.M. ASCE \\ ${ }^{1}$ Associate Professor, Civil and Environmental Engineering Department, California Polytechnic State \\ University, San Luis Obispo, CA 93407, jahanson@calpoly.edu \\ ${ }^{2}$ Senior Staff Engineer, CTI and Associates, Inc., 12482 Emerson Dr., Brighton, MI 48116, \\ lw1919@hotmail.com \\ 3ndependent Consultant, 590 Bluerock Dr., San Luis Obispo, CA 93401, nyesiller@gmail.com
}

\begin{abstract}
Analytical and numerical approaches have been developed for modeling temperatures in municipal solid waste landfills. Steps for model formulation and details of boundary conditions are described. The formulation was based on a transient conductive heat transfer analysis. Conventional earth temperature theories were modified for landfill systems by incorporating heat generation functions representing biological decomposition of wastes. Finite element analysis was used for general modeling and parametric evaluations. Thermal properties of materials were determined using field observations and data reported in literature. The boundary conditions consisted of seasonal temperature cycles at the ground surface (established using near-surface field measurements) and constant temperatures at the far-field boundary (established using field measurements and maps of regional groundwater temperatures). For heat generation, first a step-function was developed to provide initial (aerobic) and residual (anaerobic) conditions. Second, an exponential growthdecay function was established; and third, the function was scaled for climatic conditions. The formulations developed can be used for prediction of temperatures within various components of landfill systems (liner, waste mass, cover, and surrounding subgrade), determination of frost depths, and determination of heat gain due to decomposition of wastes.
\end{abstract}

\section{INTRODUCTION}

Temperatures influence the engineering properties of geomaterials. Temperature extremes and thermal cycles affect the integrity and durability of earthen and geosynthetic components of waste containment barrier systems (Rowe 2005). Determination and prediction of temperature conditions within landfill systems are needed to properly evaluate the coupled geotechnical performance of these facilities. 
Fully coupled geotechnical and thermal numerical models represent the state-of-the-art in landfill analysis.

Earth temperature theory is generally well established including coverage of temperature cycles, amplitude decrement and phase lag with depth, frost depths, ground surface temperatures, and layered systems (Carslaw and Jaeger 1959, ORNL 1981). Analytical solutions are available for thermal analysis under seasonally cyclic ground surface temperature conditions. Earth temperature theory can be applied to landfills with the addition of heat generation due to waste decomposition. Modeling the heat generation requires functions that can be incorporated using advanced numerical techniques such as finite element analysis (FEA) or finite difference approach. Numerous investigators have reported methods for modeling heat transfer in landfill systems (El Fadel et al. 1996, Doll 1997, Yoshida and Rowe 2003, Southen and Rowe 2005, Yesiller et al. 2005). Doll (1997) and Southen and Rowe (2005) used simplified constant elevated temperature conditions for modeling performance of liner systems and neglected to incorporate temporal trends of heat generation due to decomposition. El Fadel et al. (1996) developed a model for predicting heat transfer in landfills that included heat generation, but a simplified function was used (that was correlated only to estimated values of acetic acid generation rate) and losses were assumed to be linearly related to heat generation. Yoshida and Rowe (2003) developed a model that included heat generation as a function of gas production rate. Yesiller et al. (2005) quantified heat generation as compared to unheated ambient conditions, but included limited heat transfer analysis.

Limited information has been reported related to thermal analysis of municipal solid waste including heat transfer, heat generation, ground surface temperature conditions overlying wastes, and thermal properties. The objective of this paper is to outline the methodology for development of thermal modeling for landfill systems with heat generation in wastes due to decomposition, underlying native soil conditions, and overlying seasonal air temperature fluctuations. This investigation was conducted to provide material properties, model geometry and boundary conditions, heat generation functions, and overall methodology for model formulation. The analysis was conducted for landfills located in four different climatic regions in North America (Michigan, New Mexico, Alaska, and British Columbia). Transient analyses were conducted using finite element analysis.

\section{MATERIAL PROPERTIES}

For heat transfer analysis of landfills, material properties were required for the cover, waste, bottom liner, and subgrade. In particular, unit weight, thermal conductivity, and heat capacity were required. Unit weight $(\gamma)$ was determined using operational site records for earthen barrier materials, wastes, and native subgrade soils. Thermal conductivity $\left(k_{t}\right)$ was determined using laboratory and field thermal conductivity probe experiments (Hanson et al. 2000) and using data from literature (e.g., Andersland and Ladanyi 2003). Volumetric heat capacity (C) was calculated by summing heat capacity of individual components of the materials on a volumetric basis. Weightvolume relations of the soils were determined using site records and fractions of constituents of the wastes were obtained from U.S. EPA (2005). Thermal diffusivity 
$(\alpha)$ was calculated as the quotient of thermal conductivity and volumetric heat capacity. A summary of material properties used for the study sites is presented in Table 1. The thermal properties varied between the sites due to soil type, construction conditions, precipitation, and waste placement conditions. In general, both $k_{t}$ and $C$ (for wastes and soils) increase with increasing $\gamma$ and moisture content.

Table 1. Material Properties for Analyses

\begin{tabular}{|l|c|c|c|c|}
\hline Property & Michigan & New Mexico & Alaska & $\begin{array}{l}\text { British } \\
\text { Columbia }\end{array}$ \\
\hline$\gamma_{\text {waste }}\left(\mathrm{kN} / \mathrm{m}^{3}\right)$ & 9.8 & 7.4 & 5.2 & 9.8 \\
\hline$k_{t \text {-waste }}(\mathrm{W} / \mathrm{mK})$ & 1.0 & 0.6 & 0.3 & 1.5 \\
\hline$C_{\text {waste }}\left(\mathrm{kJ} / \mathrm{m}^{3} \mathrm{~K}\right)$ & 2000 & 1200 & 1000 & 2200 \\
\hline$\alpha_{\text {waste }}\left(\mathrm{m}^{2} / \mathrm{s}\right)$ & $5.0 \times 10^{-7}$ & $5.0 \times 10^{-7}$ & $3.0 \times 10^{-7}$ & $7.0 \times 10^{-7}$ \\
\hline$\gamma_{\text {soil }}\left(\mathrm{kN} / \mathrm{m}^{3}\right)$ & 20.5 & 16.7 & 21.0 & 17.7 \\
\hline$k_{t-\text { soil }}\left(\mathrm{W} / \mathrm{mK}^{3}\right)$ & 2.5 & 0.7 & 2.4 & 1.0 \\
\hline$C_{\text {soil }}\left(\mathrm{kJ} / \mathrm{m}^{3} \mathrm{~K}\right)$ & 2800 & 1300 & 1800 & 3100 \\
\hline$\alpha_{\text {soil }}\left(\mathrm{m}^{2} / \mathrm{s}\right)$ & $9.0 \times 10^{-7}$ & $4.9 \times 10^{-7}$ & $1.3 \times 10^{-6}$ & $3.3 \times 10^{-7}$ \\
\hline
\end{tabular}

\section{MODEL GEOMETRY AND BOUNDARY CONDITIONS}

The analysis has been formulated in 1-D using FEA (ABAQUS version 6.5). A series of simulations was conducted with varying degrees of mesh refinement using element sizes ranging from $0.1 \mathrm{~m}$ to $6 \mathrm{~m}$. An element size of $0.5 \mathrm{~m}$ was selected based on a relative error analysis conducted using these simulations (Cook et al. 1989). The time step for transient analysis is in part controlled by element size, and the time step was established as 1 day for most analyses.

Boundary conditions required in modeling landfill heat transfer consisted of far field boundary at depth and the ground surface boundary. The bottom boundary was established $75 \mathrm{~m}$ below the bottom liner. This depth was determined by analyzing the temperature response of different model geometries using increasingly greater depths. Simulations were conducted using variable depths below the liner system ranging from 10 to $200 \mathrm{~m}$ for 30-year simulation periods. For this parametric evaluation, the liner temperatures were assumed to be constant at $30^{\circ} \mathrm{C}$ (consistent with long-term stable field measurements in a liner system). The distance from the liner to the bottom boundary was determined to be $75 \mathrm{~m}$, the first depth at which the differential in response between the simulation for $200 \mathrm{~m}$ boundary and a nearer boundary was less than $0.1^{\circ} \mathrm{C}$. The far field boundary was fixed at the mean annual earth temperature. Mean annual earth temperatures were obtained on a site-specific basis using field measurements and data from literature for groundwater temperatures (e.g., ORNL 1981).

The ground surface boundary for landfills is highly complicated to define due to the coupled influence of wind, precipitation, snow cover, moisture evaporation, solar radiation, and heat gain from decomposition of underlying wastes. A common approach to obtain ground surface temperatures is to modify air temperatures to account for radiation absorption and emission effects using ground surface freezing 
and thawing $n$-factors (Andersland and Ladanyi 2003). Freezing or thawing indices represent the area bound by the temperature-time curve and the $0^{\circ} \mathrm{C}$ baseline (area below $0^{\circ} \mathrm{C}$ for freezing, area above $0^{\circ} \mathrm{C}$ for thawing). The $n$-factors are determined as the quotient of paired surface and air indices for freeze or thaw. These factors are typically applied on a seasonal basis to provide idealized sinusoidal annual ground surface temperature fluctuations. Surface $n$-factors are affected by climatic and ground surface conditions.

Well established surface $n$-factors have not been reported for landfill conditions. For model formulation, ground surface temperatures were determined based on an analysis of measured ground surface and near-surface temperatures. Measured ground surface temperatures were highly variable due to surface weather effects and measurement frequency. Therefore, measured near surface temperature extremes (representing maximum and minimum temperatures at each depth) were extrapolated upward to obtain two idealized surface temperature functions at each site: one for native soils and one for wastes. The resulting idealized sinusoidal ground surface temperatures were used to back-calculate $n$-factors for the sites using conventional 30year definition (Andersland and Ladanyi 2003). These $n$-factors are provided for use at other sites to determine ground surface temperatures using air temperature data (without the need for field ground surface temperature measurements). For all ground surface temperature waves, a phase lag of $\pi / 8$ was applied (Carslaw and Jaeger 1959), such that the coldest surface temperature occurred 45.6 days after the winter solstice.

A sequential model development was used that accounted for model geometry modifications with time (an excavated landfill cell below grade, waste filling, and installation of landfill cover). Chronologically, first the excavated landfill cell was modeled. The initial temperature of native subgrade soil (from bottom liner system to the far-field boundary) was uniformly set to the mean annual earth temperature. The model was then allowed to run under application of the idealized ground surface temperature function for soil. The surface temperatures were applied until long-term annual temperature cycle stasis of the subgrade was obtained. Approximately 7-10 years of simulation was required to reach this condition. Second, waste filling was modeled. The waste placement sequences were obtained from site records including annual aerial fly-over surveys, land-based topographic measurements, and detailed waste placement records. Waste placement was modeled using individual compacted lifts of approximately 3 to $5 \mathrm{~m}$. Heat generation functions are applied sequentially with waste placement to the entire column of waste. Based on field measurements of as-delivered waste temperatures, it was estimated that the waste was placed at a temperature equal to average daily air temperature. The idealized seasonal surface temperature wave was applied to the waste surface (i.e., daily cover). Third, the installation of cover system (either interim or final cover) was modeled. The initial temperature of the cover materials was assumed to be equal to the ground surface temperature on the day of installation. The idealized seasonal surface temperature wave was then applied to the cover. A summary of the parameters used for boundary conditions including back-calculated $n$-factors is presented in Table 2. Ground surface temperatures overlying wastes were generally warmer than ground temperatures of native soils, as indicated by the higher thawing $n$-factors and lower freezing $n$-factors. 
Table 2. Summary of Boundary Parameters Used in the Model

\begin{tabular}{|l|c|c|c|c|}
\hline Parameter & Michigan & $\begin{array}{c}\text { New } \\
\text { Mexico }\end{array}$ & Alaska & $\begin{array}{c}\text { British } \\
\text { Columbia }\end{array}$ \\
\hline Mean Soil Temperature, $T_{m}\left({ }^{\circ} \mathrm{C}\right)$ & 12.3 & 19.0 & 5.4 & 12.1 \\
\hline Amplitude for Soil Temperatures, $A_{s}\left({ }^{\circ} \mathrm{C}\right)$ & 17.3 & 12.0 & 13.4 & 11.0 \\
\hline Thawing $n$-factor (soil) & 1.23 & 1.24 & 1.15 & 1.07 \\
\hline Freezing $n$-factor (soil) & 0.91 & NA & 0.53 & NA \\
\hline Mean Cover Temperature, $T_{m}\left({ }^{\circ} \mathrm{C}\right)$ & 13.0 & 20.0 & 6.6 & 17.3 \\
\hline Amplitude for Cover Temperatures, $A_{s}\left({ }^{\circ} \mathrm{C}\right)$ & 16.6 & 12.0 & 14.3 & 12.0 \\
\hline Thawing $n$-factor (waste) & 1.27 & 1.31 & 1.31 & 1.53 \\
\hline Freezing $n$-factor (waste) & 0.56 & NA & 0.48 & NA \\
\hline
\end{tabular}

NA - not applicable due to lack of significant freezing at these sites

\section{MODELING OF HEAT GENERATION}

Modeling with FEA was conducted using the material properties, geometries, and boundary conditions described above. Model results were compared to measured field temperatures at each of the four extensively instrumented sites to develop heat generation functions (Liu 2007). Methodology for field measurements and analysis of results is presented elsewhere (Yesiller et al. 2005, Hanson et al. 2005). Nonlinear regression analysis was performed to establish the functions that provided the best agreement between modeled and measured temperatures (Liu 2007). The data set used for comparisons represented 4 to 8 years of temperature measurement. However, because the temperature sensors were placed in wastes of varying ages, the range of waste age documented extends from 0 to 40 years. This allowed for greater predictive significance. In general, the trends in modeled and measured temperature vs. time were similar throughout various components of the landfill systems and through the entire range of waste age available for comparison. Damping of seasonal temperature variations with depth, phase lag with depth, depth of frost penetration, and onset and presence of heat gain due to waste decomposition were captured by the modeling (Liu 2007). The modeled temperatures were generally within $\pm 2^{\circ} \mathrm{C}$ of measured temperatures throughout the entire depth of the landfill.

Heat generation functions that varied with waste age were developed. For all heat generation functions, zero heat generation rate was specified when modeled waste temperatures were either less than $0^{\circ} \mathrm{C}$ or greater than $80^{\circ} \mathrm{C}$. Heat generation was typically high for young wastes and low for old wastes. The heat generation functions were formulated to account for net heat gain due to decomposition under normal landfill operations. The functions therefore accounted for thermal losses such as convective heat flow due to leachate migration and removal. Initially, a step-function was used to model heat generation rate in wastes due to aerobic and anaerobic decomposition for the Michigan and Alaska sites. These sites were selected for the step function formulations as maximum and minimum heat gain (in relation to ambient temperature conditions) occurred at these sites (Yesiller et al. 2005). In this 
formulation it was assumed that the initial aerobic phase occurred during the first 4 months subsequent to placement of waste. Then, the waste entered the anaerobic phase and remained there for the balance of the analysis. The 4-month period was selected for the aerobic phase based on the analysis of gas concentration data from the sites (Hanson et al. 2005). The resulting limiting values (maximum and minimum) for aerobic heat generation were 11.3 and $2.5 \mathrm{~W} / \mathrm{m}^{3}$ and for anaerobic heat generation were 0.38 and $0.08 \mathrm{~W} / \mathrm{m}^{3}$, for Michigan and Alaska, respectively.

Next, a more sophisticated exponential growth and decay function (Equation 1) was used for modeling heat generation for all the sites. The format of Equation 1 was selected to provide more realistic response than a step function. The function resulted in growth of heat generation rate to a peak value followed by an exponential decay. The constants $(A, B$, and $D)$ control the peak value, the shape of the peak, and the rate of decay. Parameters were determined using best fit nonlinear regressions with field data.

$$
\begin{aligned}
& H=A\left[\frac{B t}{B^{2}+2 B t+t^{2}}\right] e^{-\sqrt{\frac{t}{D}}} \\
& \text { where, } \\
& H=\text { heat generation rate }\left(\mathrm{W} / \mathrm{m}^{3}\right) \\
& t=\text { time (day) } \\
& A=\text { peak heat generation rate factor }\left(\mathrm{W} / \mathrm{m}^{3}\right) \\
& B=\text { shape factor (day) } \\
& D=\text { decay rate factor (day) }
\end{aligned}
$$

The exponential growth and decay heat generation rate functions obtained for the four study sites are presented in Figure 1 and summarized in Table 3. The peak heat generation rate values varied significantly with the highest values for British Columbia followed by Michigan, New Mexico, and Alaska. The high rates are attributed to relatively wet and warm climates. Even though the maximum heat generation rate was obtained for British Columbia, the maximum heat gain occurred in Michigan due to thermal properties of the wastes (Yesiller et al. 2005). The variability in durations required to reach the modeled peak heat generation rate was less than the variability in peak values. Total energy expended represented the area under a given heat generation rate vs. time curve and was calculated on a per unit volume basis. The peak heat generation rate values ranged from 0.19 to $2.21 \mathrm{~W} / \mathrm{m}^{3}$, the times for peak heat generation rate ranged from 174 to 360 days, and the total energy expended ranged from 15 to $191 \mathrm{MJ} / \mathrm{m}^{3}$.

Effects of climatic and operational conditions on the peak heat generation rate values were investigated to extend the applicability of the heat generation functions to other sites. Correlations were developed for the heat generation function parameters $A$ and $B$ to a composite climatic-operational condition factor, $\lambda$, that was calculated as the product of average daily air temperature and the average annual precipitation divided by the average compacted unit weight of the wastes. A correlation was also developed between parameter $D$ and an operational condition factor, $F$, defined as the average vertical waste filling rate (m/year). The correlations are described by the following equations: 
$A=-7.92+0.12 \lambda$

$B=-2027+20.47 \lambda-0.015 \lambda^{2}$

$D=55.5+2.79 F$

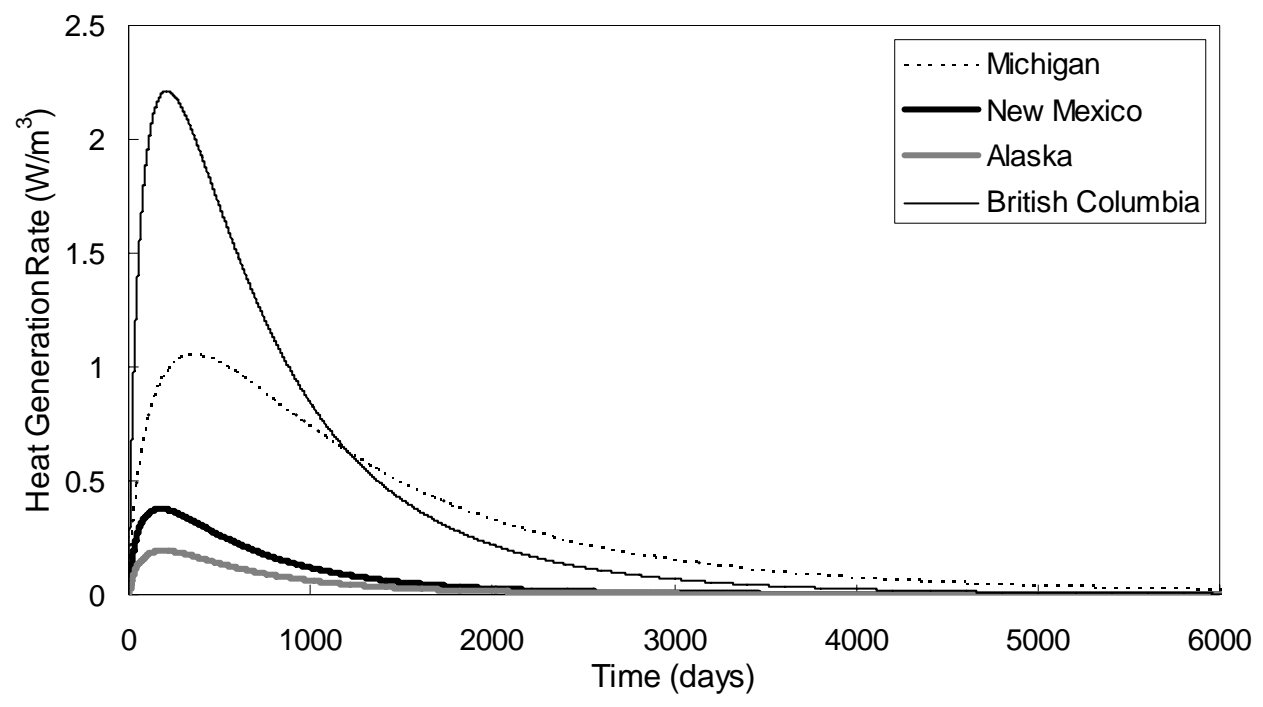

Figure 1. Exponential Growth and Decay Heat Generation Rate Functions

Table 3. Summary of Heat Generation Functions

\begin{tabular}{|l|l|l|l|l|l|l|}
\hline Site & $\begin{array}{l}\text { Peak Heat } \\
\text { Generation } \\
\text { Rate Value } \\
\left(\mathrm{W} / \mathrm{m}^{3}\right)\end{array}$ & $\begin{array}{l}\text { Duration } \\
\text { for Peak } \\
\text { Value } \\
\text { days })\end{array}$ & $\begin{array}{l}\text { Total } \\
\text { Energy } \\
\text { Expended } \\
\left(\mathrm{MJ} / \mathrm{m}^{3}\right)\end{array}$ & $A$ & $B$ & $D$ \\
\hline Michigan & 1.05 & 360 & 158.0 & 95 & 5000 & 120 \\
\hline New Mexico & 0.38 & 174 & 28.8 & 75 & 5000 & 50 \\
\hline Alaska & 0.19 & 190 & 15.0 & 7 & 1200 & 90 \\
\hline British Columbia & 2.21 & 210 & 191.0 & 130 & 2000 & 80 \\
\hline
\end{tabular}

\section{CONCLUSIONS}

Numerical modeling of temperatures in landfills requires transient, nonlinear analysis. Ground surface temperature functions overlying native soils and wastes were developed. Heat generation functions were developed that provide temporal variation in heat generation of wastes due to biological decomposition. The parameters used to define these functions have been correlated to climatic and operational conditions. The formulations described herein can be used for prediction of temperatures within various components of landfill systems (liner, waste mass, cover, and surrounding subgrade), determination of frost depths, and determination of net heat gain due to decomposition of wastes. The methodology is developed to be broadly applicable to municipal solid waste landfills in various climatic regions. 


\section{ACKNOWLEDGEMENT}

This study was supported by the National Science Foundation (GOALI Grant: CMS9813248, SGER Grant: CMS-0301032, and a 2004 AAAS/NSF WISC Grant). Assistance of the partner landfills (Sauk Trail Hills Development, Corralitos Regional Landfill, Anchorage Regional Landfill, and Vancouver Landfill) is greatly appreciated. The assistance of Mr. Nicolas Oettle with analysis is greatly appreciated.

\section{REFERENCES}

Andersland, O. B. and Ladanyi, B. (2003). Frozen Ground Engineering, 2nd Edition, Wiley, NY.

Carslaw, H. S. and Jaeger, J. C. (1959). "Conduction of Heat in Solids,” second ed., Oxford University Press, Oxford.

Cook, D. R., Malkus, S. D., and Plesha, E. M. (1989). Concepts and Applications of Finite Element Analysis (3rd edition), Wiley, NY.

Doll, P. (1997). "Desiccation below mineral liners with heat production," J. Geotech. Geoenviron. Eng., ASCE, Vol. 123, No. 11, p. 1001-1009

El Fadel, M., Findikakis, A. N., and Leckie, J. O. (1996a). "Numerical modelling of generation and transport of gas and heat in sanitary landfills: I. Model formulation,” Waste Management \& Research, ISWA, 14, 483-504.

Hanson, J. L., Yesiller, N., and Kendall, L. A. (2005). "Integrated Temperature and Gas Analysis at a Municipal Solid Waste Landfill," Proceeding of the $16^{\text {th }}$ International Conference on Soil Mechanics and Geotechnical Engineering, Millpress Science Publishers, Rotterdam, the Netherlands, Vol. 4, pp. 2265-2268.

Hanson, J. L., Edil, T. B., and Yesiller, N. (2000). "Thermal properties of high water content materials," ASTM Special Technical Publication 1374 Geotechnics of High Water Content Materials, Edil, T. B. and Fox, P. J., eds., ASTM, West Conshohocken, PA, 137-151.

Liu, W.-L. (2007). Thermal Analysis of Landfills, Ph.D. Thesis, Wayne State University, Civil and Environmental Engineering Department, Detroit, Michigan.

ORNL (1981). Regional analysis of ground and above-ground climate. Oak Ridge National Laboratory Report No. ORNL/Sub-81/40451/1, U.S. Department of Energy, Office of Buildings Energy R\&D.

Rowe, R. K. (2005). “Long-Term Performance of Contaminant Barrier Systems,” 45th Rankine Lecture, Geotechnique, 55 (9), 631-678.

Southen, J. M. and Rowe, R. K. (2005). "Modelling of thermally induced desiccation of geosynthetic clay liners,” Geotext. Geomembr., Elsevier, 23 (5), 425-442.

U.S. EPA (2005). Municipal Solid Waste Generation, Recycling, and Disposal in the United States: Facts and Figures for 2003, EPA530-F-05-003, Washington, D.C.

Yesiller, N., Hanson, J., and Liu, W. (2005). "Heat generation in municipal solid waste landfills,” J. Geotech. Geoenviron. Eng., ASCE, Vol. 131, Issue 11, 13301344

Yoshida, H. and Rowe, R. K. (2003). “Consideration of landfill liner temperature,” Proceedings, Sardinia 2003, Ninth International Waste Management and Landfill Symposium, Christensen, T. H. et al., eds., CISA, Italy. 